\title{
Revise of the undergraduate program for speciality in Applied Physics to intensify training in optics and photonics
}

Shiquan Tao, Li Wang, Zhuqing Jiang

Shiquan Tao, Li Wang, Zhuqing Jiang, "Revise of the undergraduate program for speciality in Applied Physics to intensify training in optics and photonics," Proc. SPIE 9665, Tenth International Topical Meeting on Education and Training in Optics and Photonics, 966507 (3 June 2007); doi: $10.1117 / 12.2207667$

SPIE Event: Tenth International Topical Meeting on Education and Training in Optics and Photonics, 2007, Ottawa, Ontario, Canada 


\title{
Revise of the Undergraduate Program for Speciality in Applied Physics to Intensify Training in Optics and Photonics
}

\author{
Shiquan Tao, Li Wang, and Zhuqing Jiang \\ College of Applied Science, Beijing University of Technology, Beijing 100022 China \\ (+8610)67391734, (+8610)67391738 (fax), shqtao@bjpu.edu.cn
}

\begin{abstract}
:
The Applied Physics program at Beijing University of Technology was designed to nurture innovative talent in modern applied physics, providing students both solid theoretical grounding and training for practical scientific research skills by offering 4-year BS degree. In order to fit in with the needs of the fast developing of our society, the education objectives and the program curriculum need to be correspondingly adjusted. This paper reviews the two revises of Applied Physics program, launched in 2003 and 2007 respectively.
\end{abstract}

\section{Introduction}

Beijing University of Technology (BjUT) was founded in 1960, and initially focused to high education of undergraduates in various engineering disciplines for Beijing, the capital city of China. At the beginning the main task of Physics speciality was only offering University Physics course to engineering students. As China launched the economy reform and opening to the outside world since late 1970s, the requirement of Beijing for highly-educated talent promoted BjUT to be a comprehensive university, and Applied Physics Department was built up. After thirty years developing, and especially since 1996 when the University entered the national 211 project $^{1}$, the faculty of applied physics nowadays not only provides fundamental physics courses to all the engineering students of the whole university, but also offers BSc degree in Applied Physics, MSc \& PhD degrees in Physics. The undergraduate program for Applied Physics speciality was designed to nurture innovative talent in modern applied physics, providing students both solid theoretical grounding and training for practical scientific research skills. The graduates were supposed to be employed by high education and research institutions.

However, as the economy of the society developing, the situation of enrollment and employment changes quickly. In order to fit in with the needs of the fast developing of our society, we must revise the education objectives and the program as well. This paper describes the method and the results of two revisions of the undergraduate program in recent years.

\section{Motivation and Method}

In the late 1990s, the undergraduate course curriculum of the Applied Physics speciality was aiming at presenting traditional theoretical fundamentals, and after covering the necessary theoretical concepts, introduced several specialized course in Optics, Condensed Matter Physics, and Theoretical Physics. This was to prepare graduated students for work in high education and research institutions. The problem had arisen as the economy developing rapidly: the employment threshold of high education and scientific research went up; graduates with only BSc degree in Physics felt difficult in finding jobs. At the same time, there was a common view that photonics would be a key enabling technology in the 21 st century, which would be applied to all industry and research fields. It is a crucial strategic technology demanded by Beijing. Since BjUT has been oriented to "Merging itself with Beijing, and Serving the development of Beijing", we should have more students educated and trained to work in photonics. On the other hand, optics has been one of the key disciplines in BjUT. The faculty of optics has made remarkable progress in research fields such as optical information processing, advanced lasers, fiber communication and sensing. In this situation several optics and photonics courses was added into the program during 1998-2002, and a systematic revision of the undergraduate program was conducted first in 2003.

Tenth International Topical Meeting on Education and Training in Optics and Photonics, edited by Marc Nantel, Proc. of SPIE Vol. 9665, 966507 - (C) 2007 SPIE, OSA, IEEE, ICO doi: $10.1117 / 12.2207667$ 
The latest revision has been conducted in this spring. The purpose of this revision is to decrease the total credits and intensify the practical training, which would be beneficial to students to develop their creative thinking pattern and ability to solve real-world problems. Also, through the 4-year study students would have wider knowledge and more flexibility, and would more easily emerge into various industrial sectors.

Although the program is for undergraduate students, it should be implemented by the faculty members. So in each revision we organized a Teaching Steering Committee and called all teachers into action. The professors who were in charge of the course groups organized discussions in depth. Through discussions teachers took the responsibility for providing students with new courses both in curriculum classes and in laboratory.

\section{Description of the course curriculum}

The number of total credits is, in principle, decided by the university authority. The courses can be roughly divided into four domains: General Education (G) including social science, arts, and cross-disciplinary courses; Basic Courses of Disciplines (B) including advanced mathematics, general physics, four main mechanics, and optics; Specialized Courses (S) including courses provided by teachers working in three main research directions (optics and photonics, condensed matter physics, and theoretical physics); and Practical Training (P) including laboratory experiments, workshop practice, course design projects, and final year projects.

\section{Details of the revision}

Firstly, the revision is to adjust the credit distribution of courses among the above four domains, which is listed in Table 1. It is obvious that in the 2003 revision the practical training was highly reinforced as the total credits increasing. This is because we slightly changed the educational objectives of the Applied Physics Speciality to meet the demand for highly-qualified personnel in high-tech fields with more practical skills. In the 2007 revision we maintained the proportion of practical training and increased the proportion of specialized courses, even though the total credits was reduced.

Table 1 Credit Distribution of courses for Speciality in Applied Physics

\begin{tabular}{|r|c|c|c|}
\hline \multicolumn{2}{|c|}{ Classification } & \multicolumn{3}{|c|}{ Program Version } \\
\cline { 2 - 4 } & 1999 & 2003 & 2007 \\
\hline Total credits & 192 & 217.5 & 190 \\
\hline General Education (Credits/Proportion ) & $62.5 / 32.6 \%$ & $65.5 / 30.1 \%$ & $50.5 / 26.6 \%$ \\
\hline Basic Courses of Disciplines (Credits/Proportion ) & $83 / 43.2 \%$ & $73 / 33.6 \%$ & $68 / 35.8 \%$ \\
\hline Specialized Courses (Credits/Proportion ) & $16 / 8.3 \%$ & $18.5 / 8.5 \%$ & $23.5 / 12.4 \%$ \\
\hline Practical Training (Credits/Proportion ) & $30.5 / 15.9 \%$ & $60.5 / 27.8 \%$ & $48 / 25.3 \%$ \\
\hline
\end{tabular}

Then, the revision is to adjust the proportion that the optics-related courses have in the whole program, so that the program is most suitable for the education objectives. Table 2 gives the data showing that in these two revisions the proportion of optics related courses kept increasing, reflecting the fast developing of optics and photonics.

Table 2 Credit distribution of Optics \& Photonics courses

\begin{tabular}{|r|c|c|c|}
\hline \multicolumn{1}{|c|}{ Classification } & \multicolumn{3}{|c|}{ Program Version } \\
\cline { 2 - 4 } & 1999 & 2003 & 2007 \\
\hline General Education, elective & - & - & 2 \\
\hline Basic Courses of Disciplines, required & 7 & 7 & 7.5 \\
\hline Specialized Courses, required & 7 & 8.5 & 8.5 \\
\hline Specialized Courses, elective (Total available) & $2(4)$ & $2(2)$ & $6(10)$ \\
\hline Practical Training, required & 2 & 15.5 & 13.5 \\
\hline Practical Training, elective & & & 6 \\
\hline Subtotal/proportion & $18 / 9.4 \%$ & $33 / 15.2 \%$ & $43.5 / 22.9 \%$ \\
\hline
\end{tabular}


Table 3 lists the details of courses designed for optics and photonics. In the 2003 revision, we incorporated fiber communication experiments and holographic data storage experiment ${ }^{1}$ into the Specialized Physics Experiments course, and added Optical Industrial (workshop) Practice and Optical Communication Course Project in the program. Thus the training in optics and photonics was greatly reinforced. In the 2007 revision, more elective courses both in class curricular and in laboratory were added in the program. Moreover, we designed an interdisciplinary course, Stereography \& Holographic Arts, not only for Applied Physics students, but also for all other disciplines at the University. This would be beneficial to open up new horizons for the students.

Table 3 Credit of Courses Designed for Optics \& Photonic

\begin{tabular}{|c|c|c|c|}
\hline \multirow{2}{*}{ Name of Course } & \multicolumn{3}{|c|}{ Program Version } \\
\hline & 1999 & 2003 & 2007 \\
\hline Stereography \& Holographic Arts ( $\mathbf{G}$, elective ) & - & - & 2 \\
\hline Optics ( B ) & 3.5 & 3.5 & 4 \\
\hline Principles of Lasers ( $\mathbf{B}$ ) & 3.5 & 3.5 & 3.5 \\
\hline Information Optics ( $\mathbf{S}$ ) & 3 & 3.5 & 3.5 \\
\hline Principles of Fiber Communications ( $\mathbf{S}$ ) & 2 & 2 & 2 \\
\hline Optoelectronics ( $\mathbf{S}$ ) & 2 & 3 & 3 \\
\hline Principles of Holography ( $\mathbf{S}$, elective) & 2 & - & \\
\hline Optical Communication Systems ( $\mathbf{S}$, elective) & 2 & - & \\
\hline Optical Communication Networks ( $\mathbf{S}$, elective) & - & 2 & 2 \\
\hline Crystal Optics $(\mathbf{S}$, elective $)$ & & & 2 \\
\hline Fiber Sensing Technology ( $\mathbf{S}$, elective) & & & 2 \\
\hline Applied Optics \& Optical Instruments ( $\mathbf{S}$, elective) & & & 2 \\
\hline Specialized Physics Experiments $(\mathbf{P})$ & 2 & 4.5 & 3 \\
\hline Optical Industrial Practice $(\mathbf{P})$ & & 2 & 2 \\
\hline Course Project: Optical Communication $(\mathbf{P})$ & & 9 & 4 \\
\hline Course Project: Optoelectronics $(\mathbf{P})$ & & & 4.5 \\
\hline Self-taught Course $(\mathbf{P}$, elective $)$ & & & 2 \\
\hline Course Group for Creative Activities (P , elective) & & & 4 \\
\hline Final Year Project $(\mathbf{P})$ & 14 & 18 & 16 \\
\hline
\end{tabular}

\section{Results}

The revision has given good results as expected. The situation of recruitment greatly improved as more qualified students enroll in Applied Physics each year, showing that the undergraduate program satisfies the need of the students. In recent years more graduated students obtained jobs in the field of photonics, and the number of graduates who obtained the opportunity to pursue higher degree has been increasing. However, this reflects only success of the revision during 1998-2003. The effectiveness of the 2007 revision has to be demonstrated by our teaching practice in the following years.

\section{References}

1. Shiquan Tao, Zhuqing Jiang, Dayong Wang, Yuhong Wan, "Introduction of advanced optics research to laboratory-experimental course for undergraduate teaching", Conference on Education and training in optics and photonics (ETOP2005) 